\title{
The American Academy of Pediatrics should Advise Parents to Put their Infants on their Right-Side Position Only When Sleeping. Summary of A Published Research
}

\author{
Othman Alfleesy* \\ Associate Professor of Forensic Medicine, Department of Forensic Medicine and Pathology, Faculty of Medicine and Health Sciences, Aden \\ University, South Yemen \\ *Corresponding author: Othman Alfleesy, Associate Professor of Forensic Medicine, Department of Forensic Medicine and \\ Pathology, Faculty of Medicine and Health Sciences, Aden University, South Yemen
}

\section{Introduction}

For nearly 3000 years, it has been recognized that apparently healthy infants could die suddenly and unexpectedly usually during sleep [1]. During the last 60 years an intensive study were made by researchers for this dilemma. Studies showed that sudden infant death syndrome (SIDS) has association with sleeping positions. It affects about one out of every 500-600 live births [2]. SIDS is a common cause of infant's deaths in developing countries, it is classified by Centre of disease control (CDC) as the third leading cause of overall infant mortality in USA [3]. A number of Studies showed that Apparent Life-Threatening Event (ALTE) linked to SIDS strictly while others consider ALTE as a separate entity, but they did not interpret this mystery. Up to date no study explained how they could prevent SIDS. The published research gains its importance because it gives -for the first time- a solution to preventing SIDS, which have been never suggested before. Numerous studies, flooding of theories, hypotheses, causes and risk factors were gushed but with no solution. Finally, the author postulates in his published research: hypothesis, suggesting new definition for SIDS and an explanation of ALTE, and opened doors for future studies.

\section{What is known about SIDS and ALTE?}

\section{Definition of SIDS}

In 1969, the Second International Conference on Sudden Infant Death gave the following definition for SIDS: every sudden, unexpected death of an infant where postmortem Investigations don't explain death [4]. It was universally accepted. Despite slight changes suggested in 1989 (clinical history and scene of investigation), SIDS remains a diagnosis of exclusion [1,5].

\section{The Clinical History and Manifestations of SIDS}

The history of any infant's death is repeated as follows: A child within the age of two years, in a good heath, without previous disease, put in a bed, and is either found dead in its sleeping place in the early morning, or is found dead some hours, after its early feed $[2,6]$. The infants (in both SIDS and ALTE) suffered before from: cyanosis, apnea, frightening, choking, frothy fluid, obstructive asphyxia and others. But in SIDS the infants die while in ALTE they escaped death.

\section{Autopsy Findings}

During autopsy, the pathologists found that the pathological features of SIDS as follows: intrathoracic petechiae (on thymus, heart, lungs, parietal pleura, pericardium, and diaphragmatic pleura), Pulmonary edema, frothy fluid, food in stomach. All these features are suggestive, but nor diagnostic of SIDS [1,2,5-7]. These features are found in natural and unnatural death, that is why, they diagnose SIDS by exclusion.

\section{Theories}

About more than 80 theory were proposed in the last 60 years , with no scientific explanation, some of these theories were as follows: Overlying, hypothermia, parathyroid insufficiency, CO2 toxicity, allergy to cow's milk, heavy bed clothes, sleep apnea syndrome, arousal mechanisms, cardiac arrhythmias, chronic asphyxia, hypoxia, blocked air passages....etc. Until today no uniform explanation exists, some exclusively remark upon obstructive asphyxia [8], and refer to typical signs of asphyxiation which be found very often1. Other favor reflex mostly vagal inhibition of the heart but without explanation. Others restricted their theories to apnea without determining the specific cause. There were no diagnostic criteria for SIDS and there was no accurate method for prospective study too.

\section{Risk Factors}

Some of causes, risk factors Identified in the studies of SIDS infants were : age (more in the first year), sex (more in males), seasons (more in winter), race, social class, prematurity, twins, time 
of death (more at night), all sleeping positions but mainly prone position, maternal smoking during pregnancy), bottle feeding, young maternal age, low birth weight, temperature and others $[9,10]$. Alexander et al stated: Much is known about risk factors for SIDS, however the true cause (or causes) of SIDS are still largely unexplained13.All these risk factors were of no significance as most studies determined.

\section{Sleeping Position [1,2,11-13]}

An infant's sleep position has been identified as a major risk factor for SIDS. Since 1985, investigators from around the world focused on sleep positions and no definite answer was found even after the sorrow recommendations of the American Academy of Pediatrics (AAP) to put infants on prone position which led to more deaths.After this, it was known that prone sleeping position has association to SIDS. That is why in 1992 the American Academy of Pediatrics changed their recommendation and recommended placing infants to sleep in the non-prone (back or side) position [1416]. After this recommendation, there was a decline in statistical number of deaths. They found that there is a strong association between sleep positions (mainly prone,) and SIDS. But they could not determine which position is the cause of SIDS or which one is the safe position?

\section{Apparent Life - Threatening Event (ALTE)}

Another phenomenon associated with SIDS was ALTE, which the scientists could not interpreted its nature and its relation to SIDS.A link between ALTE and SIDS has been noted in much of the literature, but due to misinterpretation of the nature of these entities the researchers failed to answer its mystery. The researchers have not delineated the differences between SIDS and ALTE infants. ALTE is defined as an episode that is frightening to the observer and that is characterized by some combination of apnea, color changes (cyanotic), marked change in muscle tone (limpness) [14]. The researchers admitted that the Survivors of an ALTE share many risk factors for SIDS. The researchers declared their confusion in concern to ALTE. The author believes that this confusion is an extension of the SIDS misconception, misinterpretation raised from no standardization of its definitions.

The failure to link between ALTE and SIDS was due to impatience for observers or caregiver to stay beside the infant's hours watching their changes. ALTE is a process of dying which might have or have not ended with SIDS. SIDS and ALTE are in the same line with two consequent stations. SIDS is the end result of some ALTE infants. Some infants are found agonizing and die before any help can be obtained. Vigorous stimulation is the only way which might revive the ALTE infant -in time- when the observer observed the infant in the process of asphyxia or dying process. An association between SIDS and ALTE was suggested because of prior ALTE events in 5\% of SIDS victims18. The investigators declared their confusion in concern to ALTE. There are clinical similarities between SIDS and ALTE, the only difference is that in SIDS the death had occurred while in ALTE the infant escaped from death. From this information it is clear that SIDS is a continuity of ALTE till death and ALTE is interrupted SIDS. It is a transit either to death or to escaping from death.

\section{Conclusion and Brief Explanation}

\section{The author believes that}

a) All previous studies were unsatisfactory.

b) The previous studies have not reached to a definite answer about the nature of SIDS in order to prevent it.

\section{It has been shown by study that}

a) There is a lack of Criteria for both definition and diagnosis of SIDS.

b) There is consensus that sleep positions (mainly prone) are associated with SIDS [1,2].

c) There is increased resistance to airflow when an infant laid prone to sleep [17].

d) The prone/supine sleeping positions could be associated with lower arousal threshold [1].

e) It was proved that an arousal is a logical defense mechanism to protect breathing during sleep [1].

f) The right-side position can have a protective function by preventing the tongue from occluding the airway when the genioglossus muscle is hypnotic [17].

g) Obstruction of the upper airway-by the back of the large and muscular tongue falling posteriorly into the hollow of a soft yielding pharynx -in sleep- may obstruct the airway and even worsen as the baby inspires, thus enhancing negative pressure below the block $[5,18]$.

h) Mechanical occlusion and upper airway obstruction are favored by prone positions and increased airflow resistance [17].

i) Negative esophageal pressure is higher in supine / prone positions [18].

j) It is well known that hypoxia, stimulates the vagal inhibition [18].

k) The right-side sleeping position never studied or tested before through the history of studies.

\section{There Are Many Known Facts Regarding the Body Structures, And from Studies We Found That}

a) Laying on Right side will ensure smooth breathing and lowering the resistance to breathing because the right bronchi remains in a good straight position and the short right lung will be in contact having a good right thoracic space. Hence the trachea will change its shape and length accordingly [1,17].

b) The liver in the right side of the body constitutes the base on which other organs lay down directly or indirectly in this position as it is the heaviest organ of the body.

c) Laying on right side position permits to establish a suitable direction to the stomach with its content of food that facilitates a smooth breathing. 
d) The distention and pressure (mainly upward) by stomach - after ingesting food -upon the diaphragm well be decreased by this position.

e) The heart and left lung positioned in the upper side in the mediastinum gives the person an opportunity to breaths easily and gives the heart \& lung an opportunity to beat and move freely.

f) The clinical similarities between SIDS and ALTE are suggestive for their having the same risk factors, common causes, and mechanisms. All these similarities give a clue to the nature of SIDS.

\section{Conclusion}

\section{The Right-Side Sleeping Position Hypothesis}

Based on the previous data, the author concludes that the current information, facts, and knowledge resulted in this study established the validity on which the hypothesis and suggested definition were based on: So in an effort to solve this controversial problems the author wishes to put forward his right side sleeping position hypothesis to prevent SIDS as follow: If an infant be placed for sleeping on right side position after having breastfeeding then SIDS would be prevented.

\section{Recommendation}

The revision recommended that healthy infants be positioned on their right-side position, rather than on other positions when being put-down a sleep. And the AAP American Academy of Pediatrics should review its opinion.

\section{Acknowledgement}

Finally, I would like to thank Edwin Mitchill, Professor of Child Health Research Department of Pediatrics, and University of Aukland, New Zealand, who sent me his scientific opinion about my study. He declared that no studies have reported on the difference between right and left side sleeping position and stated: this is a testable hypothesis. And I emphasize again, it is true that no study before had determined certainly that right side position is the safe position during sleeping.

\section{References}

1. Keens TG (1996) Sudden infant death syndrome. Pediatric potpourri, state of the Art 1996 university, children's, Medical group, Maui, Hawaii 181.
2. Schwartz PJ, Southall DP, Valdes Dapena M (1988) The sudden infant death syndrome. Cardiac and respiratory mechanisms and interpretations. Ann N Y Acad Sci 533: 1-474

3. Athanasakis E, Karavasiliadou S, Styliadis I (2011) The factors contributing to the risk of sudden infant death syndrome. Hippokratia 15: 127-131.

4. Valdes Dapena M (1986) Sudden infant death syndrome. Morphology update for forensic pathologist-1985. Forensic Sci Int 30: 177-186.

5. Rintahaka PJ, Hirvonen J (1980) The epidemiology of SIDS in Finland in 1969-1980. Forensic Sci Int 30: 219-233.

6. Sawaguchi T, Sawaguchi A, Fujita T, Kobayashi M (1994) Statistical estimation of diagnostic accuracy of SIDS in Japan. ACTA MEDICINAE LEGALIS, XLIV:296-298.

7. Shapiro GHA (1988) Forensic Medicine. A guide to principles ( $3^{\text {rd }}$ edn.), Churchill London.

8. Willinger M, Hoffman HJ, Wu KT, Hou JR, Kessler RC, et al. (1998) Factors associated with the transition to nonprone sleep positions of infants in the United States: The National Infant Sleep Position Study. JAMA 280: 329-335.

9. Consensus statement (1987) National Institutes of Health Consensus Development Conference on infantile Apnea and Home Monitoring. Pediatrics 79: 292-299.

10. Bergman A, Ray CG, Pomeroy MA, Wahl PW, Beckwith JB (1972) Studies of the sudden infant death syndrome in King County, Washington. III. Epidemiology Pediatrics 49: 860-870.

11. Markestad T, Skadberg B, Hordvik E, Morild I, Irgens LM (1995) Sleeping position and sudden infant death syndrome (SIDS): effect on an intervention pro-gramme to avoid prone sleeping. Acta paediatr 84 : 375-378.

12. Irgens LM, Markestad T, Baste V, Schreuder P, Skjaerven R, et al. (1995) Sleeping position and sudden infant death syndrome in Norway $1967-$ 1991. Arch Dis Child 72: 478-482.

13. Kaada B (1994) Why is there an increased Risk for sudden infant death in prone sleeping? Fear paralysis and atrial stretch reflexes implicated? Acta Paediatrica 83: 548-557.

14. Kattwinkel J, Brooks J, Myerberg D (1996) Positioning and SIDS. AAP Task Force on Infant Positioning and SIDS. Pediatrics 98: 1216-1218.

15. Penzel T, Möller M, Becker HF, Knaack L, Peter JH (2001) Effect of Sleep Position and sleep stage on the collapsibility of the upper Airways in Patients with sleep Apnea. Sleep 24: 90-95.

16. Skatvedt 0, Grogaard J (1994) Infant sleeping position and inspiratory pressures in the upper airways and oesophagus. Arch Dis Child 71: 138140.

17. Cordner M, Willinger M (1995) The definition of the sudden infant death syndrome. symposium IV: SIDS A259.

18. Krongrad E, ONeil L (1986) Near miss sudden infant death syndrome episode. Pediatrics 77: 811-815. 
This work is licensed under Creative Commons Attribution 4.0 License

\section{To Submit Your Article Click Here: Submit Article}

DOI: $10.32474 /$ SJO.2019.02.000141

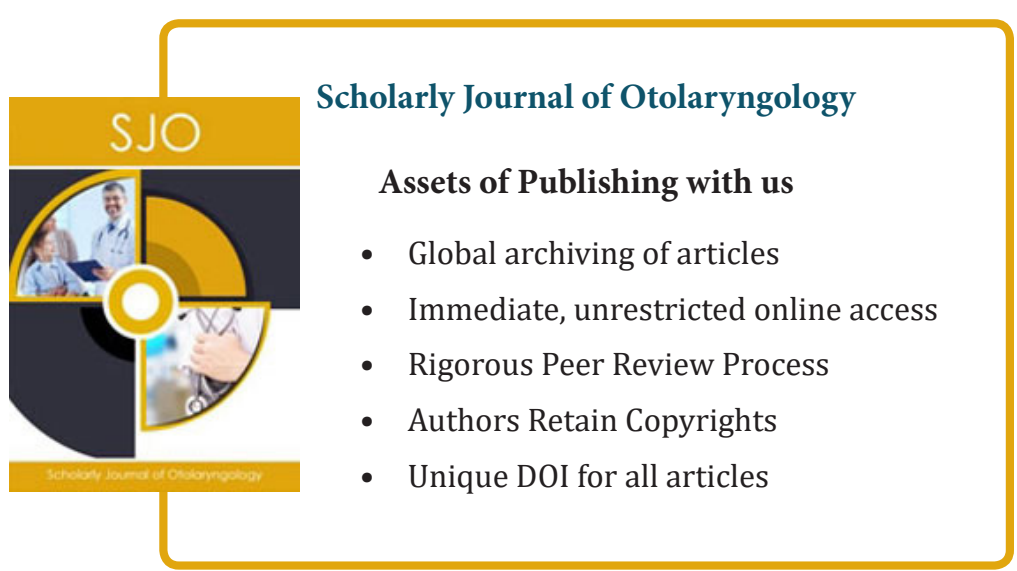

